\title{
A Glimpse of Hong Kong “Chineseness”: Pre-existing Tunes as the Redemption of a Cultural Identity
}

\author{
LEUNG Tai-wai David \\ Independant Scholar, Hong Kong China
}

\begin{abstract}
When the umbrellas were held up against the tear gas attack in the protest on September 28, 2014, the hot issue raised by the marathon-like Yellow Umbrella Movement was not only the matter of politics but also a coincidence created for the Hong Kong locals to face, or to be faced with an already moot cliché: How the Hongkongese can redefine and redeem their almost lost socio-cultural identity, particularly under the increasingly hegemonic influences and the socio-cultural invasion of the mainland after the 1997 Handover. My present paper is not intended to discuss the topic of identity on the platform of politics, or the postcolonial studies such as transculturation or cultural hybridty. But instead, I am far more interested in locating such issue on the aesthetic dimension of collective memory, which is revealed in two local contemporary Hong Kong compositions. In the process of shaping and reshaping a form of "HongKongeseness" in which the composers tend to create and the local listeners tend to experience, albeit transient, can appear in every nuance of the sonic metaphor embedded in the pre-existing indigenous tunes of a self-contained compositional work.
\end{abstract}

Keywords: Aesthetics, Cantonese Folk Lullaby, Cantonese Language, Cantonese Opera, Cantopop, Cantonese Tones, Chineseness, Collective Memory, Cultural Identity, Hong Kong Chineseness, Melodic Fragment, Metaphorical Respresentation, Nostalgic Childhood, Operatic Vocality, Possession, Quotation, Tang-song poetry (唐宋詩詞), Voice, Yellow Umbrella Movement, Zi Hou (子喉)

\section{Preface}

Nowadays Hong Kong people are fervent in talking about identity, but only few of them can touch the core of the topic. The issue is clear. To many of the locals, an "identity" that can let them be distinguished from the mainland Chinese, however vague, is crucial. This is because such identity that has already been proved as a value and pride from the 80s onward seems lost. No matter how the Hong Kong identity is meant for, this just reflects what Mercer has asserted: “...identity only becomes an issue when it is in crisis, when something assumed to be fixed, coherent and stable is displaced by the experience of doubt and uncertainty."1

Doubtless the decade in the 80s is a period embedded with special meanings in the minds of many Hong Kong people. In Liang Mouchun’s (梁茂春) monograph on Hong Kong composers and their music, Xianggang

LEUNG Tai-wai David, MPhil (Music Theory), Music Department, The Chinese University of Hong Kong; MPhil (Musicology), Department of the Humanities, The University of Hong Kong.

${ }^{1}$ K. Mercer, Welcome to the Jungle: Identity and Diversity in Postmodern Politics, in J. Rutherford (Ed.), Identity, Community, Culture, Difference, (London: Lawrence and Wishart, 1990), p. 43. 
zuoqujia: Sanshi zhi jiushiniandai (香港作曲家: 三十至九十年代) [Hong Kong Composers: From the Thirties to The Nineties], this heyday could be described as the period of “Rising Generation” (起飛的一代), a generation that paralleled with the amazing economic boom and socio-cultural prosperity in the same decade. ${ }^{2}$ Not only the people in the mainland China were influenced by the importing Hong Kong pop cultures, immersing themselves in hearing and singing the Cantopop, ${ }^{3}$ but also the city of Hong Kong, as a regional member, joined the International Society of Contemporary Music (ISCM), one of the most important worldwide music organizations to help promote contemporary artmusic in 1984. No doubt this remarkable decade inaugurated a new chapter for the development of Hong Kong music, meaning that more and more local compositions could get the opportunity to be published in the mainland as well as in the international musical scene, in order to uphold the indigenous cultures for the other Cantonese speaking communities.

From the year 1997 to this day, the political as well as the socio-cultural conflict between mainland China and Hong Kong has still not yet been settled. To many Hong Kong people, doubt and uncertainty always lie ahead. Even further exacerbating the recent crisis, I believe, can retrace to the time when the umbrellas were held up against the tear gas attack in the protest on September 28, 2014. In fact, the hot issue raised by the marathon-like Yellow Umbrella Movement was not only the matter of politics but also a coincidence created for the locals to face or to be faced with the already moot clichés: "How can the Hongkongese redefine themselves if their valuable ‘identity' has been lost?”, “How can the Hong Kong 'Chinesesness' be reclaimed?”, “What does this newly recreated 'face' look like, particularly under the increasingly hegemonic influences from all aspects of the mainland?”. No matter what the answers will be, it is true that all losses must be compensated. Similarly, the loss of the past unique "identity" of Hong Kong locals must also be redeemed.

The present discussion does not aim to explore the topic of identity on the platform of politics or postcolonialism such as transculturation, although it is unavoidable to touch such areas. On the contrary, I am far more interested in locating the issue on the aesthetic dimension of collective memory, which is revealed in two contemporary Hong Kong compositions. Both works contain pre-existing tunes quoted from traditional Cantonese music, as the core value for redeeming a unique socio-cultural identity for the locals. They are Tung Lai Shing's The Book of Laughter and Forgetting (笑忘書), (2002), and Chan Hing Yan's The Enigmas of the Moon (月謎), (1998). In the process of shaping and reshaping a new face of "Chineseness”, in which the musical sounds tend to create, and the local listeners tend to experience, albeit transient, can appear in every nuance of the sonic metaphor as the redemption of a lost socio-cultural identity.

\section{Quotation, Aesthetics, Memory}

The use of pre-existing music (borrowed tune) in a new composition is not an uncommon compositional practice. For centuries, composers have incorporated quoted materials into newly composed pieces, ranging from

\footnotetext{
${ }^{2}$ See chapter 6 and 7of Liang Mouchun’s book. See Maochun Liang, Xianggang zuoquijia: Sanshi zhi jiushiniandai 香港作曲家: 三十至九十年代 (Hong Kong Composers: From The Thirties to The Nineties) (Hong Kong: Joint Publishing, 1999), pp. 200-272.

3 The main vernacular for seven million locals is Cantonese, a dialect that already covers one billion of world's population. Hence, the Hong Kong popular song is also called "Cantopop”. Throughout the history, only the China mainland has got the power to influence Hong Kong both politically and culturally. It seems that the 80s is the only time that Hong Kong could exert her cultural impact back onto the mainland.
} 
short motives to entire themes. From the Renaissance parody masses by Dufay to the gigantic symphonic works by Mahler, musical quotation can serve the expression of a symbol of national character, a metaphor of cultural identity or a nation's cosmological and philosophical ideas, manifesting diversity of referential meanings as well as aesthetic significances. Hence, even a tiny, isolated sonic quote can be a valuable conceptual framework upon considering of memory.

By its very nature, memory refers to the past. Yet it is an active process taking place wholly in the present. Upon recalling the mind stretches back to the remote past and makes it seem as though the present has come to a halt. The act of recall, whether voluntary or involuntary, is a medium through which to gain a sense of time past, the distance between the then and now, the experience as it was and it is. It challenges the moving force of time, inducing a temporary shift of time and space between one's present reality and a known or imagined past. From this sense, memory is not only confined to the sphere of psychology, cognitive or medical sciences, but aesthetics.

In addition, Susanne Langer went so far to regard memory as "a special kind of experience, because it is composed of selected impressions, physical strains, expectations and minute, undeveloped reactions." ${ }^{4}$ Recall sifts all these interrelated materials and seems to represent them in the form of moving images within a multidimensional series of events. Memory, therefore, is a personal way to aesthetically reconstruct the past in terms of the present. Similarly, like shards of an ancient relic, a glimpse of the fleeting images of memory evoked by musical sound is sufficient to arouse aesthetic response, transporting one's mind into another world of a particular milieu in the remote past, even without capacity for one to thoroughly recognize. This just simply explains how a recognizable and familiar quote can operate on the aesthetic dimension. No matter how transient the sonic image is, such familiarity can evoke one's intimate feeling of belonging to "something”, say, a culture, a place, or a person. The musical sound goes through the interactions of the listener's memory and response that a unique identity can be metaphorically formed, shaping a new socio-cultural "face" as such.

\section{Collective Memory and Cultural Identity}

While Weeks J. claims that "identity is about belonging, about what you have in common with some people what differentiates you from others," ${ }^{5}$ such an identity can also be a metaphorical manifestation in the form of possession, which is a sense of aesthetic feeling differentiating your social group or community from the others. Indeed, this feeling of possession operates in not only the personal but also the collective dimension. For many Hong Kong listeners, this very sense of owning something is largely caused by a special style or type of music, traditional music in particular, purporting to evoke their collective memory of belonging to, or being possessed in, the indigenous cultures. However, such feeling of possession is not always strong enough to be conjured up to form an "identity", except when the society is in an urgent need.

In the past few years, there has ever been such a critical time that the Hongkongese are so eagerly to uphold an independent "Chinese" face for the sake of differentiating themselves from that of the mainland people. For

\footnotetext{
${ }^{4}$ Susanne K. Langer, Feeling and Form: A Theory of Art Developed from Philosophy in a New Key (New York: Charles Scribner's Sons, 1953), p. 263.

5 J. Weeks, "The Value of Difference" in Identity, Community, Culture, Difference, Rutherford J. Ed. (London: Lawrence and Wishart, 1990), pp. 88-100.
} 
the current local Cantonese speaking people, the awareness of preserving indigenous cultures has been raised to an unprecedented level. According to Maurice Halbwachs, "people within a society reorganize or re-possess of as their shared common legacy, whether tangible or intangible, can be termed collective memory." ${ }^{6}$ From this sense, there "exists a collective memory and social frameworks for memory; it is to the degree that our individual thought places itself in these frameworks and participates in this memory that it is capable of the act of recollection."7 Despite its alleged autonomous status, music unquestionably can serve as a powerful platform for the operations of memory within the temporal dimension of our experiences, both in our everyday life and, albeit in a different form, in the ritualized context of the concert hall experience. Therefore, the indigenous cultures, regardless presented in the form of Cantonese language, Cantonese traditional opera or Cantonese folk lullaby, however fragmental, can be claimed as the shared common legacy of Hong Kong locals, since the Cantonese-speaking people still occupies the majority of the total population today. Given that Hong Kong's present critical politic-cultural climate, musical quotations found in both Tung's and Chan's orchestra pieces can be illustrative of the workings of collective memory to call for an aesthetic experience of possession, shaping and reshaping restlessly a temporary face of Hong Kong “Chineseness” for the local listeners.

\section{Tung’s Hong Kong “Chineseness” in Cantonese Operatic Tradition}

The Book of Laughter and Forgetting (笑忘書) was written by Tung Lai Shing, a Hong Kong composer steeped in the local cultural background, for the commission of Hong Kong Sinfonietta in the year 2000. Apart from the melodic quotations of diverse styles employed in this work, the most compelling element to the local listeners is mainly his choice of a quoted fragment derived from the Cantonese operatic tune, "Hallucination and Sorrow of Parting” (幻覺離恨天) from Hong Lou Meng [The Dream of the Red Chamber] (紅樓夢), written by the well-known deceased Cantonese operatic librettist Yip Shiu-tak (葉紹德, 1929-2009), for a charity fundraising concert in $1964 .^{8}$

Taking a preliminary glance at the composition title of Tung's work, listeners may feel trapping in a labyrinth. What is the meaning of this title? It seems to mind a possible, yet vague, connection with Milan Kundera's now-famous novel of the same name. In addition, Tung made a special reference for the title of second movement to one of the book's chapters, "The Angel.” Doubtless this title brings listeners an impression of the miserable life and inescapable fate of the two figurative lovers in both of the fiction and opera; that come parallel to the tragic and elusive story of the relevant Chinese classical literature, Hong Lou Meng, [The Dream of the Red Chamber] (紅樓夢). Such gloomy, hopeless view of life seems to delineate a similar political, socio-cultural scene for the current Hong Kong listeners, opening a broader imagined space for much contemplation.

After the opening muted divided strings murmur a varied melodic fragment quoted from the Prelude of Verdi's renowned opera La Traviata, displaying a delicate female image of sorrowful life, several shattering of "international" percussive sounds such as shakuhachi-like flutes, Tibetan singing bowls, African bongos, and

\footnotetext{
${ }^{6}$ Maurice Halbwachs, On Collective Memory, Lewis A. Coser Transl. and Ed. (Chicago: The University of Chicago Press, 1992), p. 22.

Ibid, p. 22.

${ }^{8}$ Some refer to a collection of Cantonese operatic songs published by the mainland claiming that Cantonese opera Hou Lau Meng(紅樓夢)—“Hallucination and Sorrow of Parting (幻覺離恨天)”, was written by another famous Cantonese operatic librettist, Tang di-sheng (唐滌生).
} 
South America marimba attempt to arouse anticipation of the listeners. But these purposeless strikings have not bought any significance to come.

Not until the third moment of the ponderous percussive proclamation then a female voice unexpectedly bursts out. The singer suddenly utters a disjointed two-syllable Cantonese phrase: "thinking of the secular world (思凡)” (example 1). This extremely exaggerated melisma holds over the listeners for more than twenty-three seconds. By incorporating a real human voice into the pure instrumental colored fabric, Tung seems to create a new "voice" unexpectedly to catch the attention of the listeners, inviting them to think broader and deeper. The singing voice now matters not in the semantic meaning of the words or in the provenance of the quoted tune. It is the voice delivery prior to whatever is spoken. Simply put, tone comes before words. While the meaning is always embedded in the musical notes, understanding abstractly in terms of interval, motif, and harmony, the expression can also lie in the physicality of the voice and its mode of performance. In this very moment, what shock the local listeners are not the diverse timbral sounds; but instead, a real human vocality, which is characterized by its qualities of sound wrapped in a complex combination of rhythm, volume, contour, and more importantly, the language tone of Cantonese per se, rather than the words of what the singer has just sung. 

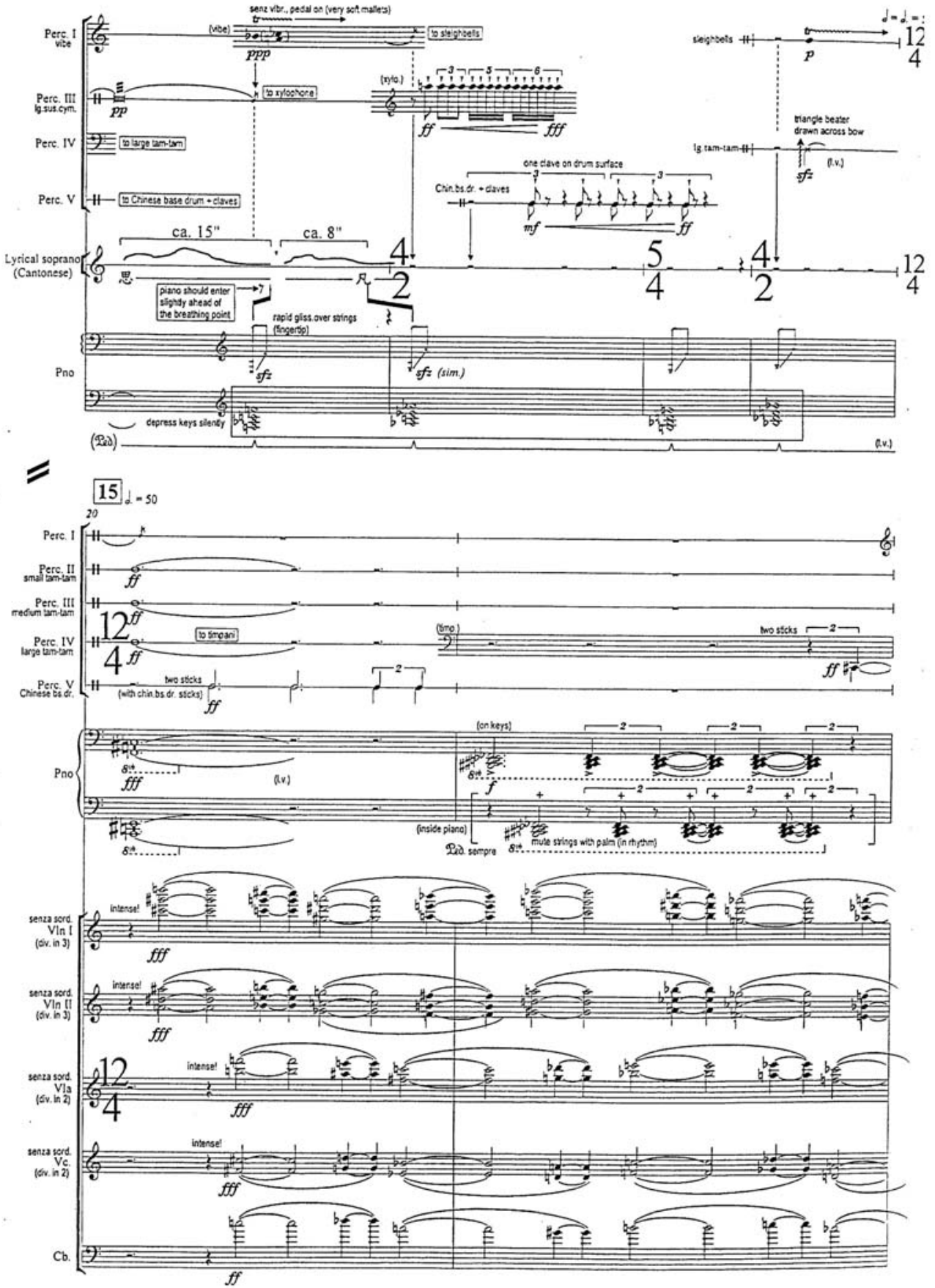

Example 1. Tung’s Quoted Tune from Traditional Cantonese Opera.

The power of music to trigger memory is without question. According to Maurice Halbwachs, "[historical memory] can only be stimulated in indirect ways through reading or listening..."9 Hence, there is no surprise that such act of recollection triggered by the musical sound have time and again challenged the destructive force of time, and drop-by-drop they have woven a memorable, yet imagined, form of legitimized culture of a particular community. For the local listeners, the collective memory evoked largely lies in the appearance of the female

\footnotetext{
${ }^{9}$ Ibid, p. 22.
} 
vocality, Zi Hou (子喉) (operatic soprano), ${ }^{10}$ which is a special vocalization of the traditional Cantonese opera. In fact, Cantonese traditional opera has long been regarded as a legitimized local cultural legacy advocated by the ex-colonial Government since the 1970s, so as to stabilize the political climax at that time after the riot in 1967. The success of preserving Cantonese opera as a theatricalized form definitely demonstrates that it is a valuable cultural possession for the local community. Thus, hearing an operatic genre as a metaphorical representation of a self-cultural identity is not without reason.

Another enticement that is able to evoke a collective memory comes from the Cantonese tone itself. Perhaps, some may suggest that Tung's adaption of such an indigenous material enshrined in a western orchestral framework may be a mere compositional strategy to search for novel style and diverse sounds. This might be true if the local listeners heard this piece in the year 2000 when the composition was premiered. At that time, just no more than three years after the 1997 Handover, Hong Kong people were still immersed in the dream and hope of a bright future because of their seemingly audacious faith on China Government's implementation of "One Country Two System” that was carved in the Basic Law. Doubtless they would be enthralled by the sonic complex of multifarious exotic and indigenous collage, which can easily exhibit a paramount multicultural image of the cosmopolitan Hong Kong. But to many of the today's local listeners, especially those have experienced the 2014 Yellow Umbrella Movement, their attentions may be easily drawn on to the Cantonese tone itself, which can be regarded as a distinctive, yet minor, sound independently protruding from the surrounding "foreign" sonic stratums. It is the moment not important to hear what words have been recited. Such aesthetic experience is very similar to that of the Viennese audience experiencing in 1804, when they firstly heard the unstable $\mathrm{Eb}$ arpeggiated theme hovering in the beginning measures of Beethoven's Eroica Symphony (Symphony no. 3 in Eb Major, op. 53) in the première concert. At that time, Napoleon's army had already occupied Vienna and brought forth political threat and storm to the city. Thus, the Viennese listeners only heard the "heroic" theme as a fearful and anxious provocation, instead of a lively, elegant passage of a conventional symphony.

The listening experience of the 19th Century Viennese audience just reminds us of a widely-known statement: context defines meaning; a particular context defines a particular meaning. Such saying is also congruent with what Andrew Simpson has claimed about "identity". Indeed he said: "In the attempted construction and maintenance of national identities, language has regularly been assumed to have a highly significant role to play... [and language can also] serve to unite its population in a shared national identity."11 Similarly, in Tung's music, the sudden intruding Cantonese tone can be experienced as the redemption of the "language" itself, since Cantonese has been gradually losing its value and authentic status because of the politic-cultural corrosion from the mainland after the reunification in 1997. To many local listeners at this very moment, Cantonese is no longer a kind of periphery Chinese "tone"-a regional dialect—-that the China Chairman Xi Jin Ping (習近平) asserted publicly not long time ago. On the contrary, Cantonese seems to regain

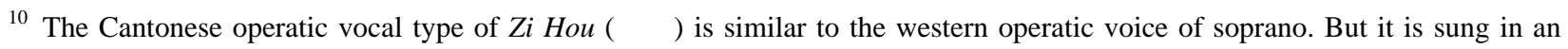
extremely high pitched falsetto like voice of boy. Another Cantonese operatic vocal type which is sung in ordinary voice is Peng $\mathrm{Hou}$ (平喉). Whether a male or female singer, he/she usually sings in Peng Hou (平喉) to the male character of the opera.

11 Andrew Simpson, “Introduction” in Language and National Identity in Asia, Andrew Simpson ed. (Oxford: Oxford University Press, 2007), p. 4.
} 
its vital life that belongs only to the Hong Kong people, becoming part of their own prestigious possession. Hence, hearing the Cantonese vocal tone as such is parallel to what the local extreme nativists have been upholding recently through different social campaigns: safeguarding the Cantonese as the authentic mother-tongue, not the Putonghau, for Hong Kong people. Hence, both of the Cantonese vocal tone and the indigenous operatic genre become the "collective possessions" for the local Cantonese-speaking community. From this sense, Tung's work probably can exhibit a Hong Kong Chinese face, however transient, to the local listeners.

\section{Chan’s “Hong Kong Chineseness” in Cantonese Folk Lullaby}

While the quotation in The Book of Laughter and Forgetting (笑忘書) emphasizes the aesthetic significance of Cantonese language and operatic genre, the quoted tune employed in “Terra Lumiere (地霜)", the fifth movement (last movement) of Enigmas of the Moon (月謎) for huqin, cello and orchestra, just exhibits the cultural power of Cantonese traditional folk music.

In 1998, just one year after the reunification of Hong Kong and China, Hong Kong Sinfonietta, which is a communal orchestra renowned for promoting new art music of Hong Kong composers, also the sponsor of Tung Lai Shing's The Book of Laughter and Forgetting (笑忘書), commissioned Chan Hing Yan, another active local composer, to write Enigmas of the Moon (月謎). ${ }^{12}$ Indeed, the memorable tune quoted in Chan's work is adapted from, Yue Guang Guang (月光光), or in English “The Shining Moon”, which is a popular lullaby spreading around the Cantonese-speaking territory of the Southeastern China. This song is not solely an oral-traditional lullaby passing through generations by generations through the lips of mother. Instead, it has already been popularized by stepping into the local pop song repertoire, pervading the Cantonese-speaking communities and pleasing the music lovers for many years. One of the popular Cantopop albums containing "Yue Guang Guang" [The Shining Moon] (月光光) is released by Cheung Tak Lam (張德蘭), a famous local pop singer, and is collected in her album entitled Yue Guang Guang (月光光) (CD no. PLCD-18-1032) published by Silver Planet Production in 2003. Hence, the moment when the local listeners recognize this quoted tune, the aesthetic feeling of possession of, or belonging to, the Hong Kong homeland can easily be stirred up. But the evocative power of the familiar tune of "Yue Guang Guang” (月光光) is not limited as such.

While the "Yue Guang Guang” (月光光) fragmented tune moves on, several brutal, and somewhat alienated, orchestral clusters impede its normal journey. Similar to that of the effect created by the operatic quote in Tung's composition, it is not the colored orchestral sound but the indigenous folk melody that captivates the local ears. Whenever the nostalgic huqin plays the textless tune “Yue Guang Guang” (月光光), a memorable, yet imagined, picture of a peaceful Hong Kong homeland is created, since this lullaby is a beautiful tune for soothing a sleeping baby (example 2). Furthermore, the original lyric of "Yue Guang Guang” (月光光) can also touch the heart of the local listeners if they can recall the text—a nuance depiction of painstaking life of the local grass-roots. Even a fragmentary tune, however subtle, can be replete with cultural, yet sentimental, recollection.

\footnotetext{
12 Chan Hing Yan graduated with the First Class Honors at the Chinese University of Hong Kong in 1992. He continued his studies in composition and ethnomusicology at the University of Illinois. He received his doctoral degree in composition (minor study in ethnomusicology) in 1996. He is now the Head of the Music Department of University of Hong Kong. Besides teaching, Chan also published several compositions including Impressions of Bamboo, Seven Images of the moon and Watery Lustre.
} 


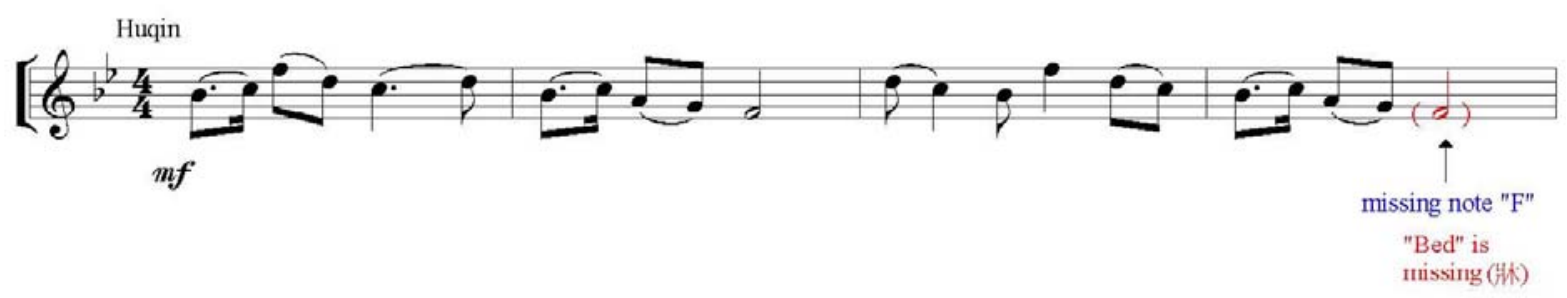

Example 2. Chan’s Quoted Tune from Cantonese Folk Lullaby (Yue Guang Guang).

Moreover, Chan's choice of quoting from the folk tune also reflects his deep reverence for the Chinese traditional poetic culture, the ancient Tang-song poetry (唐宋詩詞). This can be reflected from Chan's own description in the program note. It reads: "The Tang dynasty poet Li Bo (669-762) left a number of works where the moon played an important role but was never directly mentioned. The title Enigmas of the Moon (月謎) and its subtitles are hence forth derived." ${ }^{13}$ Chan's description of the work just shows that not only the main title but also the last movement title, “Terra Lumiere (地霜)”, is associated with the renowned ancient Tang poet, Li Bai (李白, 701-726), and his popular poem—Yejingsi (夜靜思) [A Tranquil Night]. The first two lines of this poem reads:

\section{Before bed, there is bright moonlight, (床前明月光), Perhaps, it is the frost on the ground. ${ }^{14}$ (疑是地上霜)}

It is clear that the last few Chinese words of the second poetry line just mean “terra lumiere (地霜)”, the same words borrowed for Chan’s movement title. For many local listeners, what the ancient poet Li Bai (李白) left behind is not just the beautiful poems but a marvelous cultural legacy of the whole nation that all the Chinese, especially the Hongkongese, can be really proud of. Is it not a vivid face of "Chineseness" that the music purports to create? To listeners, the main title of Chan's work containing an image of shining moon is not merely for expressing a Romantic sentiment, or directly relating to the main theme of "moon"; but to some extent, for carving a unique cultural portrait of traditional Chinese face for the attentive listeners, leaving them an aesthetic space for further appreciation.

It is no need to discuss again how the Cantonese-tone per se can function as a metaphorical representation of Hong Kong "Chineseness". But far more important is that the quoted huqin tune now is able to convey a new poetic meaning to the locals, when it is played in the form of "song without words", which is also a musical genre consisting of a collection of character pieces enhanced by the 19th-century composer, Felix Mendelssohn, in his piano cycle with the same generic name. ${ }^{15}$ From Beethoven to Mahler, the issue of western symphonic work with

\footnotetext{
13 The program note is included in both Chan Hing Yan's unpublished original manuscript and the CD album entitled Enigmas of the Moon (月謎) released by Hugo Productions (HK) Limited in 1999 (CD no. HRP7205-2). My reference is cited from Chan's unpublished manuscript.

14 The English translation of Li Bai’s Yejingsi (夜靜思) [A Tranquil Night] has many different versions. But I use my own translation here to illustrate my point. See Xu Yuanzhong, Loh Beiyei and Wu Juntao, eds. Three Hundred Tang Poems: A New Translation (Hong Kong: The Commercial Press, 1996), p. 125.

15 Felix Mendelssohn has written a famous piano cycle entitled Songs Without Words op. 19.
} 
vocal voice always centers on how a new "voice" of particular meaning is raised from the autonomous orchestral expression. If the instrumental passages imitate the "human voice without the presence of real human voice, they draw on the idea of human voices, reworking the idea of singing in the putatively more inward, abstract medium of orchestral music." ${ }^{16}$ Thus, the textless song passages are to be understood like a speaking voice, aiming to impart and to tell, potentially for speaking out from the wordlessness. From this sense, Chan's pure instrumental quote still contains the unspoken tone of the concealed words. To those listeners who have already been familiar with the original lyric of "Yue Guang Guang” (月光光), this imitated human "voice” seems murmuring the soundless "words" clearly to them, however subtle and discontinued. What is the meaning of these murmuring “words” in the lyric? The first line of "Yue Guang Guang” (月光光) discloses the answer (example 3). It reads:

The shining moon, shines upon the floor. (月光光, 照地塘)

My lovely baby, you'd better go to sleep on [bed]. (蝦仔你乘乘䀟落 [牀] )

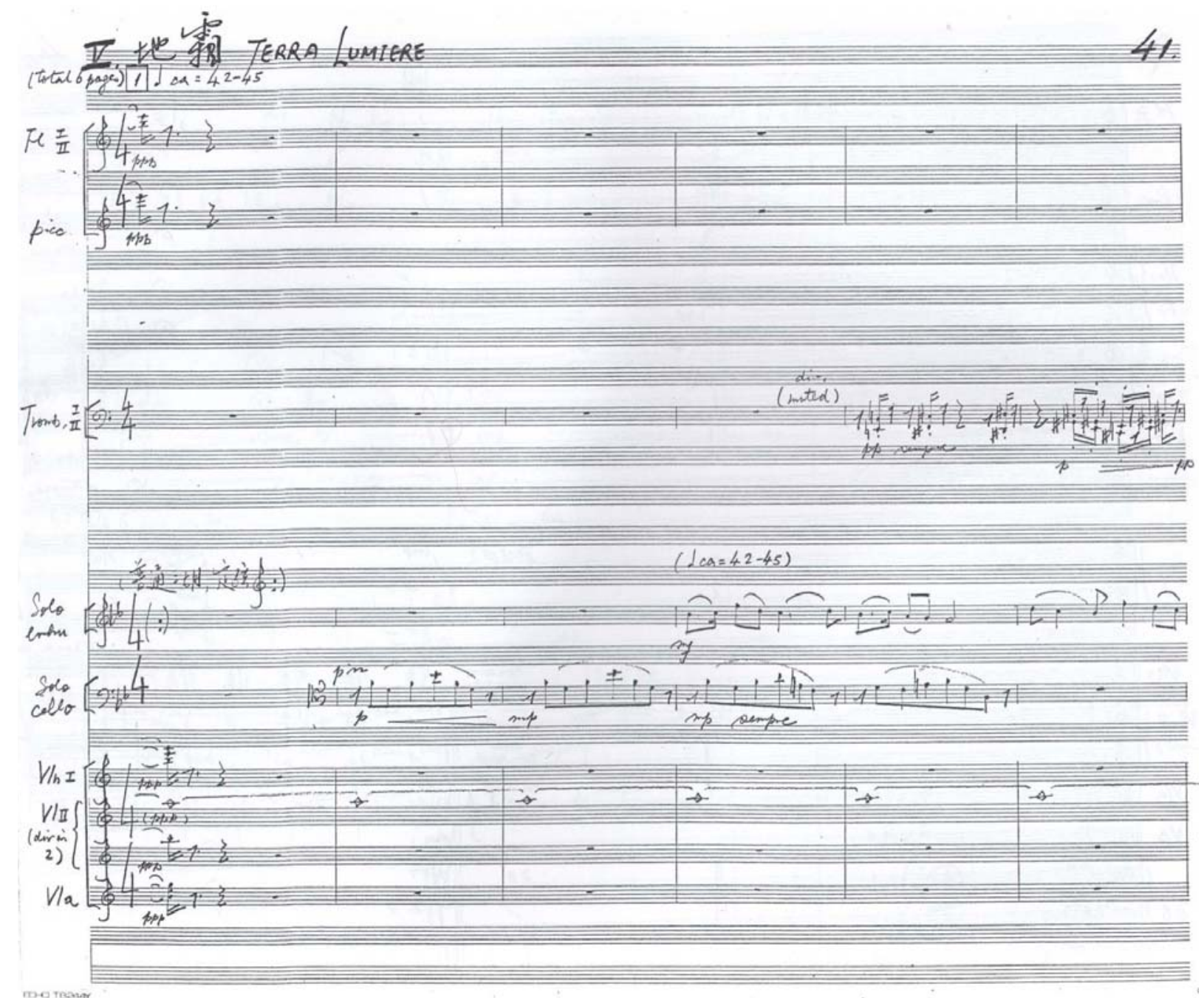

Example 3. The Missing Word in the Lyric of “Yue Guang Guang” (月光光).

16 Julian Johnson. Mahler's Voices: Expression and Irony in the Songs and Symphonies (Oxford: Oxford University Press, 2009), p. 18. 
Doubtless the original text of the traditional Cantonese lullaby can easily evoke local listeners a feeling of possession, triggering not only an immediate recollection of their nostalgic childhood but also a silhouette of the past Hong Kong life. For many cultures of different nations, Chinese in particular, childhood is a putative symbol of purity and innocence. After the piercing sonic streams have stormed in the previous movement, Chan's pure and innocent tune is unexpectedly heard, dispersing a placid, yet saccharine, tune murmuring along the local listening ears. The folk lullaby never fails to smooth listeners' hearts, comforting them to a calm and peaceful state. The anxieties and wearies, which may be originated from the current exhaustive way of living, uncertain prospect and unstable political future, now are seemingly swept away. In fact, memory is always originated from missing and longing, which emerges from a loss. For the indigenous locals, is it a recollection of the past British colonial heyday in the 1980s because something is missed today? Hearing as such is largely due to Chan's quoted tune failing to compensate a loss in his music, since the crucial F note is missed in the important cadential point to bring a full close to the movement. In the lyric of the original folk, the Cantonese word “bed” (牀) accompanies with the F note, the tonic note of the quoted tune. But now both the musical note and the word are absent, leaving the phrase with an unstable open-ending. In the Chinese traditional culture, the word “bed” (牀) always symbolizes a peaceful, stable family life. Perhaps, yearning for the "bed-like” serenity and a moment of stability is important for the Hong Kong locals today, especially after the 2014 Yellow Umbrella Movement.

The remaining music seems continuous to move purposelessly in the "homeless" or "bed-less" journey. The juxtapositions of several dissonant blocks of sound mass, together with the discursive melodic gestures, just reflect that all heavy efforts paid to reach the stable cadential goal seem futile. Even approaching the final statement of the entire piece, the music has still not reached the tonic goal. Does it imply that the “Bed” (牀) is never there to satisfy Hongkongese for a stable home? Nevertheless, Chan's crafty strategy never fails to illustrate that the unsung missing words can function as a psychological catalyst, aiming to recall a collective memory for many local listeners, and at the same time, evoking a nostalgic feeling of loss-a real Hong Kong Chinese face to which they want to re-possess.

\section{Conclusion}

To conclude, the presence of pre-existing tunes in a self-contained musical piece expands not only the scope of musical materials but also the dimension of what composers can do with these materials, as well as the imagined terrain of how listeners can acquire a new level of understanding of the same materials in a particular context. Quoted tune can function as a representation of one's act of recall, operating in every aesthetic state of collective memory. It is this socio-cultural recollection that has the power to take over local listeners' hearts and minds, never leaving them indifference and idle. As we have pointed out, to many nowadays Hong Kong locals, the glamour of the memorable past has faded out. The "identity" that represents the pride and dignity of Hong Kong "Chineseness" has also been lost. Therefore, only a precious collective memory, perhaps, can remain in the minds of many locals as a form of compensation. Be it a fragment of Cantonese language tone, a vernacular genre of opera and vocality, or a Cantonese folk lullaby in both Tung's and Chan's pieces, a musical quotation can be a tangible link between the socio-cultural reality of the past and those of the present, enhancing an aesthetic feeling of possession by means of a sonic picture, from which a glimpse of new socio-cultural face of Hong Kong "Chineseness" is created and recreated restlessly as the redemption of the loss of a Hong Kong cultural identity. 


\section{References}

CHAN, H.-Y. (1999). Enigmas of the moon. In Enigmas of the Moon. Program note. Hugo Production (HK) Ltd., CD no. HRP7205-2.

Halbwachs, M. (1992). On collective memory. (L. A. Coser, Trans. and Ed.). Chicago: The University of Chicago Press.

Johnson, J. (2009). Mahler's voices: Expression and irony in the songs and symphonies. Oxford: Oxford University Press.

Langer, S. K. (1953). Feeling and form: A theory of art developed from philosophy in a new key. New York: Charles Scribner's Sons.

Liang, M. C. (1999). Xianggang zuoquijia: Sanshi zhi jiushiniandai 香港作曲家: 三十至九十年代 (Hong Kong Composers: From the Thirties to the Nineties). Hong Kong: Joint Publishing.

Mercer, K. (1990). Welcome to the jungle: Identity and diversity in postmodern politics. In J. Rutherford (Ed.), Identity, community, Culture, difference. London: Lawrence and Wishart.

Simpson, A. (2007) Introduction. In A. Simpson. (Ed.), Language and national identity in Asia. Oxford: Oxford University Press.

Weeks, J. (1990). The value of difference. In J. Rutherford (Ed.), Identity, Community, Culture, difference. London: Lawrence and Wishart.

XU, Y. Z., LOH, B. Y., \& WU J. T.(Eds.). (1996). Three hundred Tang poems: A new translation. Hong Kong: The Commercial Press. 